\title{
Seeing chromosome structure reveals its function
}

\author{
Kiichi Fukui • Toshiyuki Wako
}

Published online: 13 March 2021

(C) The Author(s), under exclusive licence to Springer Nature B.V. 2021

Keywords Chromosome imaging $\cdot$ CHIAS $\cdot$ Super resolution microscopy $\cdot \mathrm{SEM} \cdot \mathrm{TEM} \cdot \mathrm{HIM} \cdot$ Live imaging $\cdot 3 \mathrm{D}$ imaging

This special issue titled "Imaging approaches for chromosome structure" consists of five reviews and three original articles. They describe methods for chromosome image analysis and advanced microscopic technologies employed in chromosome structural assessment. Since image analysis is an indispensable technique for analyzing the chromosome structure, application of newly developed microscopic technologies is expected to contribute approaching the chromosome structure in a way that has never been seen before.

This special issue contains the following four parts: part 1 covers both the history and the future of chromosome image analysis with a review article (Fukui and Kato); part 2 describes new research

Responsible Editor: Beth A. Sullivan

K. Fukui $(\bowtie)$

Graduate School of Pharmaceutical Sciences, Osaka University,

Suita, Osaka 565-0871, Japan

e-mail: kfukui@bio.eng.osaka-u.ac.jp trends in perceiving chromosome structures by optical microscopes, with particular attention on fluorescence microscopes, which have been undergoing many innovations recently (Botchway et al. and Mimori-Kiyosue); part 3 introduces innovations in the field of electron microscopy in which Dwiranti et al. and Phengchat et al. discuss new developments in chromosome structural research focusing on SEM and TEM, respectively; in the final part 4, Sartsanga et al., Ushiki et al., and Bhartiya et al. report the latest research results obtained by a structural analysis method not typically included in conventional microscopic techniques. Short summaries of individual articles are as follows:

Part 1. Image analysis in chromosome structure assessment (Fukui and Kato)

Fukui and Kato's review of image analysis methods focuses on the results obtained using the chromosome image analyzing system (CHIAS), while giving an

\section{T. Wako}

Institute of Crop Sciences, National Agriculture and Food Research Organization, Kannondai, Tsukuba, Ibaraki 305-8602, Japan e-mail: wako@affrc.go.jp 
overview of other image analysis methods. CHIAS was developed in 1985 and is now represented by its fourth version, CHIAS IV. This image analysis method is mainly used for the identification of plant chromosomes, and those of rice and Brassica were objectively identified using CHIAS (Fukui and Iijima 1991; Kamisugi et al. 1998). Here condensation profile (CP), an image parameter extracted from the uneven condensation pattern appearing in the prometaphase chromosome, was used.

Part 2. Advances in optical microscopy (Botchway et al. and Mimori-Kiyosue)

In chromosome studies which employ optical microscopy, a variety of fluorescent probes are used for multifarious targets having specific purposes. In order to determine not only the location of the targets but also a microenvironment of the fluorescent probes, fluorescence lifetime imaging microscopy (FLIM) has been developed (Lakowicz et al. 1992). Both light and fluorescence microscopes are limited to about $200 \mathrm{~nm}$ spatial resolution (Abbe 1873). Advances in microscope optics coupled with the development of fluorescent probes enabled the emergence of super-resolution microscopy (SRM) that surpasses the resolution limit down to $20 \mathrm{~nm}$ (Matsuda et al. 2010). Its detailed mechanism and applications are reviewed by Botchway and colleagues. Moreover, Mimori-Kiyosue provides the evidence that in addition to spatial resolution, the time resolution also has been improved. Lattice lightsheet microscopy (LLSM), developed in 2009 (Huisken and Stainier 2009) and achieving a substantial performance improvement in 2014 (Chen et al. 2014), enables the capture of a whole three-dimensional image of a mitotic cell in subsecond intervals. Mimori-Kiyosue reviews the mechanism and applications of the LLSM in detail.

Part 3. Innovations in electron microscopy (Dwiranti et al. and Phengchat et al.)

The inner structure of chromosomes is not yet completely understood. The focused ion beam/ scanning electron microscopy (FIB/SEM), introduced and reviewed by Dwiranti et al., was developed originally in the field of material science and has recently been applied to biological materials including whole chromosome imaging (Schroeder-Reiter et al. 2009;
Wako et al. 2020). Serial sections (slices) can be taken and observed using this method in an electron microscope chamber. By reconstructing and processing these cross-sectional images, internal chromosome structure has been visualized in three dimensions as illustrated on the cover of this special issue. Another approach to investigate chromosome inner structure is by combining electron tomography and electron diffraction in transmission electron microscopes (TEM), which is reviewed by Phengchat et al. One of the advantages of TEM tomography is that it allows taking non-destructive 3D images of a target.

Part 4. (Sartsanga et al., Ushiki et al., and Bhartiya et al.)

Helium ion microscopy (HIM) is one of the newly developed nanofabrication imaging techniques (Jones et al. 2013). It emits positively charged helium ion beams to interact with sample surfaces and subsequently detects effectively emitted electrons such as secondary electrons possessing lower charge-up effects. Sartsanga et al. report a detailed surface structure of a barley chromosome by using HIM. Another approach designed to achieve a nanometer resolution is the scanning probe microscopy (SPM). In particular, scanning ion conductance microscopy (SICM, Hansma et al. 1989), presented in detail by Ushiki et al., has an advantage, which reflects in the opportunity to observe soft materials such as biological samples. SICM further enables observing objects in solution environments since the scanning probe makes no contact with a sample. Ushiki et al. also analyzed the specific conditions needed to capture clear metaphase chromosome images. X-rays have a shorter wavelength than visible light and great penetration power. Therefore, it is expected that the employment of Xrays would enable obtaining the inner chromosome structure with high resolution. Here Bhartiya et al. report X-ray ptychography as a tool for measuring individual chromosome weight. This method has the potential to reveal minute differences in the chromosomes' weight, which would implicate chromosome identification by their weight as well as the degree of radiation damage to chromosomes after irradiation due to weight gain or loss.

Given the rapid advances in visualization technology, presented in the eight articles introduced in the foregoing, it is plausible that, in the foreseeable future, significant advances in understanding the structure of chromosomes will be reached. The advent of superresolution microscopy, especially in the field of light 
microscopy, has made it possible to approach the detailed structure of chromosomes even more easily (Poonperm et al. 2015). In addition, a fusion of new features with traditional electron microscopy opens up a field of great potential, as particularly seen in FIB/SEM (Wako et al. 2020). These new technologies will provide conclusive information on various structural backgrounds with implementation in genetics, cell biology, and biochemical research. In order to understand living things as a whole, it is crucial not only to understand their functional aspect but also to understand their structural foundations.

As guest editors, we would like to thank our colleagues for contributing to this special issue and for providing extraordinary work results even under this exceptional pandemic situation. We are very grateful to the responsible editor, Professor Beth A. Sullivan, for the professional guidance and cordial support throughout this process from its very beginning. We also appreciate the hard and complex work of the entire production team. Finally, we hope that our efforts will contribute to the overall progress of chromosome science as a whole.

Abbreviations CHIAS, Chromosome image analyzing system; $C P$, Condensation profile; FIB/SEM, Focused ion beam/Scanning electron microscopy; FLIM, Fluorescence lifetime imaging microscopy; HIM, Helium ion microscopy; LLSM, Lattice light-sheet microscopy; SICM, Scanning ion conductance microscopy; SPM, Scanning probe microscopy; SRM, Super-resolution microscopy; TEM, Transmission electron microscopes

\section{References}

Abbe E (1873) Beiträge zur Theorie des Mikroskops und der mikroskopischen Wahrnehmung. Arch Mikrosk Anat 9(1): 413-468. https://doi.org/10.1007/BF02956173

Chen B-C, Legant WR, Wang K, Shao L, Milkie DE, Davidson MW, Janetopoulos C, Wu XS, Hammer JA, Liu Z, English BP, Mimori-Kiyosue Y, Romero DP, Ritter AT, LippincottSchwartz J, Fritz-Laylin L, Mullins RD, Mitchell DM, Bembenek JN, Reymann A, Böhme R, Grill SW, Wang JT, Seydoux G, Tulu US, Kiehart DP, Betzig E (2014) Lattice light-sheet microscopy: imaging molecules to embryos at high spatiotemporal resolution. Science 346:1257998. https://doi.org/10.1126/science.1257998

Fukui K, Iijima K (1991) Somatic chromosome map of rice by imaging methods. Theor Appl Genet 81:589-596Hansma PK, Drake B, Marti O, Gould SA, Prater CB (1989) The scanning ion-conductance microscope. Science 243:641643. https://doi.org/10.1126/science.2464851

Hansma PK, Drake B, Marti O, Gould SA, Prater CB (1989) The scanning ion-conductance microscope. Science 243:641643. https://doi.org/10.1126/science.2464851

Huisken J, Stainier DYR (2009) Selective plane illumination microscopy techniques in developmental biology. Development 136:1963-1975. https://doi.org/10.1242 /Dev.022426

Jones MS, Huynh C, Kasuboski JM, Ferranti D, Sigal YJ, Zeitvogel F, Obst M, Burkhardt CJ, Curran KP, Chalasani SH, Stern LA, Goetze B, Fitzpatrick JAJ (2013) Helium Ion Microscopy (HIM) for the imaging of biological samples at sub-nanometer resolution. Sci Rep 3:3514. https://doi. org/10.1038/srep03514

Kamisugi Y, Nakayama S, O'Neil CM, Mathias RJ, Trick M, Fukui K (1998) Visualization of the Brassica selfincompatibility S-locus on identified oilseed rape chromosomes. Plant Mol Biol 38:1081-1087. https://doi. org/10.1023/a:1006036100987

Lakowicz JR, Szmacinski H, Nowaczyk K, Johnson ML (1992) Fluorescence lifetime imaging of free and protein-bound NADH. Proc Natl Acad Sci 89:1271-1275. https://doi. org/10.1073/pnas.89.4.1271

Matsuda A, Shao L, Boulanger J, Kervrann C, Carlton PM, Kner P, Agard D, Sedat JW (2010) Condensed mitotic chromosome structure at nanometer resolution using PALM and EGFP-histones. PLoS One 5(9):e12768. https://doi. org/10.1371/journal.pone.0012768

Poonperm R, Takata H, Hamano T, Matsuda A, Uchiyama S, Hiraoka Y, Fukui K (2015) Chromosome scaffold is a double-stranded assembly of scaffold proteins. Sci Rep 5: 11916. https://doi.org/10.1038/srep11916

Schroeder-Reiter E, Pérez-Willard F, Zeile U, Wanner G (2009) Focused ion beam (FIB) combined with high resolution scanning electron microscopy: a promising tool for 3D analysis of chromosome architecture. J Struct Biol 165:97-106. https://doi.org/10.1016/j.jsb.2008.10.002

Wako T, Yoshida A, Kato J, Otsuka Y, Ogawa S, Kaneyoshi K, Takata H, Fukui K (2020) Human metaphase chromosomes consist of randomly arranged chromatin fibres with up to 30nm diameter. Sci Rep 10(8948):1-6. https://doi.org/10.1038 /s41598-020-65842-z

Publisher's note Springer Nature remains neutral with regard to jurisdictional claims in published maps and institutional affiliations. 